\title{
Durability and modern technologies of strengthening culverts and animal crossings
}

\author{
Adam Wysokowski ${ }^{1, *}$ \\ ${ }^{1}$ Faculty of Building, Architecture and Environmental Engineering, University of Zielona Góra, \\ Prof. Z. Szafrana St 1, A-8, 65-417 Zielona Góra, Poland
}

\begin{abstract}
The paper discusses selected issues regarding to repair and reinforcing methods of the of culverts and animal crossing structures. Information was also provided on materials used for construction, and renovation of culverts. In addition, the paper discusses the most commonly used technologies of reinforcing and reconstructing these objects. Particular attention has been paid to the ways of selecting the reinforcement method and systems, taking into account the properties of the materials used in the renovation of these structures. In addition, the paper, according to the author, arranges also issues related to the proper performance of renovation for road culverts.
\end{abstract}

\section{Introduction}

Culvert structures has been built since the first roads and railway lines were created. They were built in different periods and materials, which is why we are dealing here with a very large construction diversity of these objects. Their architectural form is also very varied. Many of these structures are monumental objects, often of exceptional historical and technical value (although sometimes their values are not appreciated).

The intensive development of transport infrastructure in our country, as well as the introduction of new materials and technologies, has led to the introduction of modern culverts in engineering practice in recent years. Their modernity is mainly based on new material solutions of casing pipes (or other shapes), and cooperation with the soil in transferring operating loads. It is closely related to new expressways and highways as well as railway lines.

However, it should be taken into account that around 35 thousand of the subject engineering structures are inventoried during the currently operated roads in our country. Their technical condition often leaves much to be desired. In the opinion of the author of the paper, this condition results from the fact that these objects are underestimated due to their small dimensions compared to bridges. However, it should be noted that these facilities perform the same functions, and their importance in the transport infrastructure is just as important [1].

\footnotetext{
* Corresponding author: awysokowski@infra-kom.eu
} 


\section{Durability of culvert structures}

The service life of the culvert structures is directly related to the type of their construction, the materials from which they were made, the quality of construction, operational factors (including the intensity of load, number of over-load vehicles), environmental factors and moreover with the quality of maintenance.

We deal with a different durability in the case of culverts made of traditional materials such as stone, brick or non-reinforced concrete. These are usually massive objects, which are in operation for many years. Their durability is related due the method of maintenance and operation. Defects and lack of mortar, various types of cracks, foundation and slopes leaching lead to rapid degradation of these structures. In modern culvert structures, e.g. buried flexible steel structures, their durability is mainly determined by the durability of the shell structure, including the durability of corrosion protection, but also the method of making the backfill and its proper drainage system.

Due to the technical condition of the culverts mentioned above, as well as the increasing traffic and road load, there is a great need to strengthen and rebuild them. In addition, road projects often concern the extension of existing roads, adapting them to the new standards, and thus often involve the necessity of extending existing road culverts.

Then there is a need to determine the proper usefulness of existing construction elements in order to use them in the new structure. In the case of culverts, it is mainly necessary to determine the degree of depletion of the main structural element - in this case - the load bearing structure of the culvert with closed or open cross-section. The determination of the technical condition should also be based on the correct assumed service life after carrying out the necessary renovation, reconstruction or reinforcement. On the basis of this assessment, we are able to choose the optimal system for repairing or strengthening the existing structure of the culvert, and appropriate materials for this purpose.

Photographs in Figures $1-6$ present examples of unsatisfactory technical condition of currently used road culvert structures.

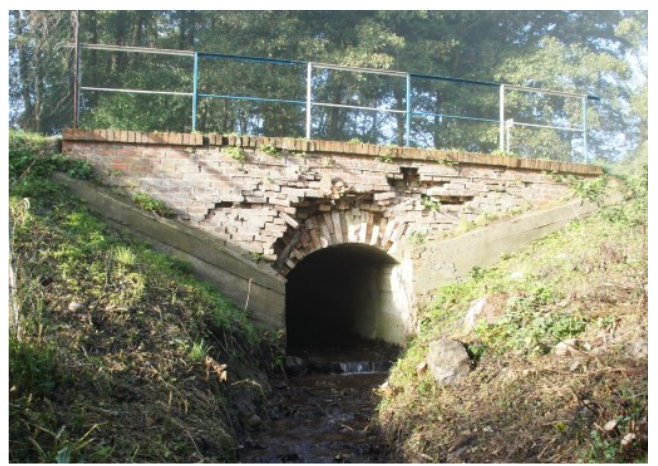

Fig. 1. An example of damages of road culvert made as brick structure (photo by Author).

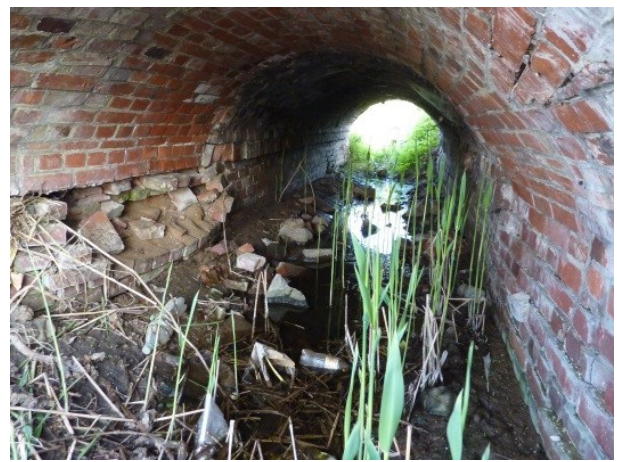

Fig. 2. Example of structural damages of arch brick culvert (photo by Author).

As is generally known, intense technological progress in the field of materials engineering allows for the creation of more and more modern materials for the culvert structural elements, which are characterized by better parameters, both strength and durability. 


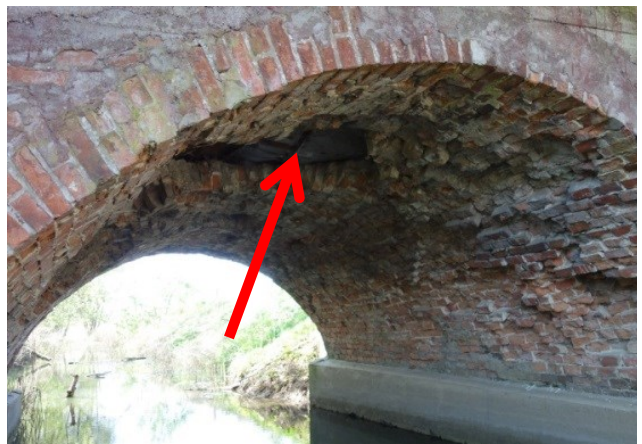

Fig. 3. Example of material loss from the construction of brick arch (photo by Author).

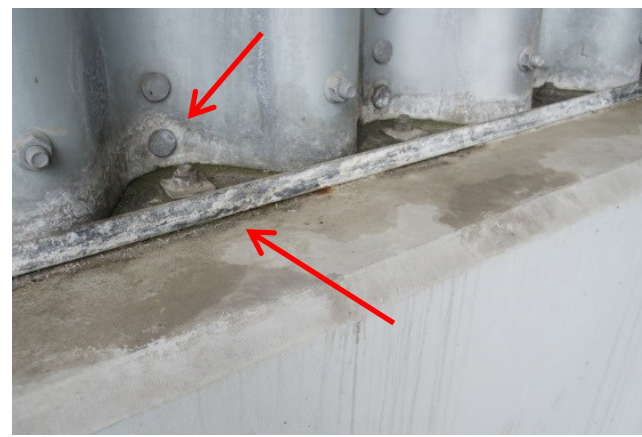

Fig. 5. An example of corrosion of a culvert made of corrugated steel buried structure (photo by Author).

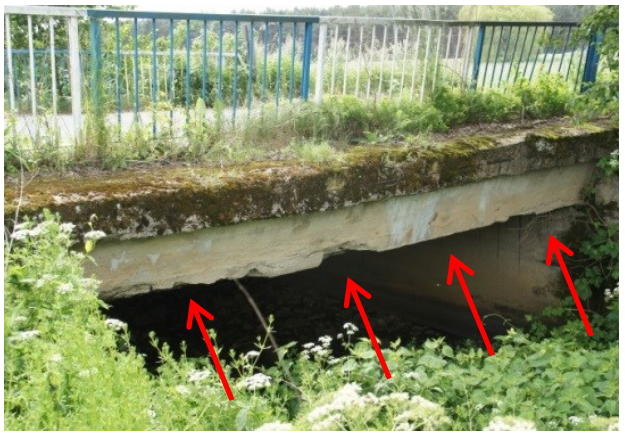

Fig. 4. An example of damage of a reinforced concrete road plate culvert (photo by Author).

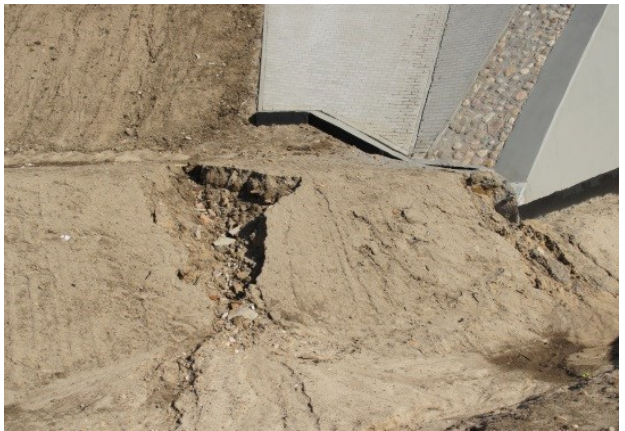

Fig. 6. An example of structural damage of slope within the structure (photo by Author).

This applies to both plastic technology (PP, HDPE, etc.), composite materials (GRP, CCGRP) as well as modifications of traditional materials (concrete mixes, PCC, etc.). This translates directly to the operational durability of new wells, as well as overhauled or reinforced traditional culverts.

\section{Technologies and methods of reinforcing culvert structures}

Currently, many new technologies have been developed for reinforcing culverts using modern materials. These technologies ensure both the durability of the reinforced structure as well as its usability. They mainly consist in restoring the original load capacity or increasing it depending on the construction needs. These technologies contribute both to extend the service life as well as improve the aesthetic and architectural applications.

The systems of this work include both the use of additional supporting structures in the form of construction pipes or composite sleeves, as well as the use of highly modified materials in the field of construction materials $[2,3]$.

Table 1 presents the currently most commonly used methods of reinforcing the construction of culverts. 
Table 1. Currently used methods of reinforcing the culvert structures.

Relining method
(the so-called "tube-in-tube" method).
This method is characterized by the fact that it
enables reinforcement of culverts without the need
to disassemble an existing facility and stop road
traffic (taking into account the technical condition
of the existing structure).
Modern construction materials.
Strengthening these structures involves structural
repair and filling of existing cavities, scratches and
cracks, with modern, highly modified, non-
shrinking materials.
Modern composite reinforcing sleeves.
Thanks to the innovative curing process the sleeve
can be used as an independent bearing structure.
methods and other technologies, e.g. chemical
anchors.
of other repair methods and additional reinforcing
elements, e.g. additional reinforcing structures

\subsection{Reinforcing the culverts using the Relining method}

The most commonly used modern technologies for reinforcing the discussed structures are the relining method, ie the use of additional supporting structures. The idea of the discussed method is basically the insertion of an additional supporting structure with a circular crosssection or other into the existing reinforced pass, and then filling the space between the object and the reinforcing structure with additional material [4]. As a result of using this technology, a "quasi" composite structure is created consisting of a reinforced object, a filling material and a reinforcing structure [5]. It is important to calculate the object's light in such a way that the "new" culvert meets the intended parameters of use [6]. As the supporting structures are used corrugated metal sheets, plastics and composite materials and also prefabricated reinforced concrete structures.

In the case of using corrugated steel pipes to reinforce culverts of smaller diameters, are most commonly used closed cross-sections MultiPlate structures. In the case of objects with greater vertical and horizontal dimensions, it is possible to use open box structure in 
e.g. Boxculvert type [7]. The open cross-sections used in this case provide better vertical and horizontal dimensions for the reinforced structure after renovation or reconstruction.

As plastic relining pipes for this type of reinforcement are generally used pipes made of high-impact polyethylene HDPE. The inner wall of the pipes is smooth, while its outer surface has the shape of a spiral notch with the size and pitch of the coil dependent on the diameter of the pipe [8]. This construction gives a good combination of hydraulic and capacity parameters. The additional external corrugation of pipes, (similar as in the case of corrugated steel), enables additional "anchoring" of the relining pipes - especially in the longitudinal direction - in the filling material between the new and existing structure.

An example of using a PE pipe to strengthen the culvert is shown in Figure 7.

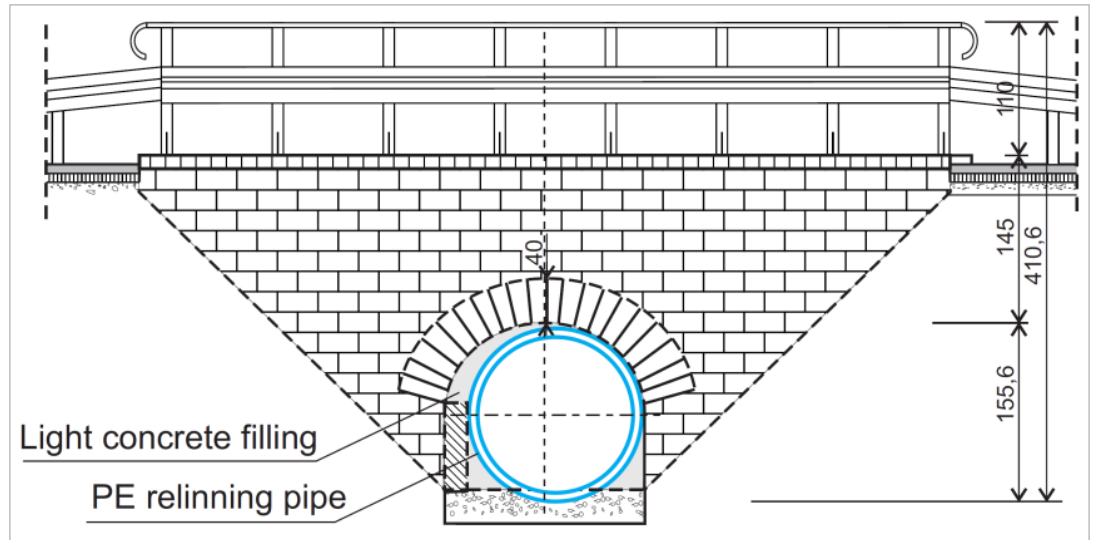

Fig. 7. An example of using a PE pipe to reinforce the brick culvert structure.

Commonly used GRP and CC-GRP composite pipes are also commonly used in the case of this reinforcement technology. In addition to high strength, they are characterized by a competitive flow rate (especially made in CC-GRP technology), with increased resistance to abrasion.

There are various materials and technologies to fill the free space between the reinforcing structure. In the case of a large area necessary for filling, mainly gravel-sand mixtures or appropriately modified concrete mixes are used. The choice of filling material depends mainly on the shape of the cross-section of the reinforced object. The task of the filling material is to ensure optimal cooperation between the culvert and the reinforcing structure. For this reason, it is very important to accurately and correctly fill this space so as to prevent the formation of air voids, which cause local concentration of stress during the subsequent operation of the culvert [9]. However, it cannot be high-strength concretes due to the previously mentioned cooperation of new and old bearing structure. The latest solutions in this field include concrete mixes with a liquid consistency with an expansive additive, i.e. allowing the exact filling of free spaces.

As already mentioned, due to the intensive development of transport infrastructure, and consequently the need to build new and reconstruct roads, there is often a need to "extend" the existing culverts. This involves widening existing roads to the new standards, and perform additional functions - e.g.. sidewalks and bike lanes. Rebuilding of the these object consists in "adding" additional bearing structures adapted to the existing vertical and horizontal dimensions of the existing culvert.

Examples of such solutions are shown in Figure 8. 

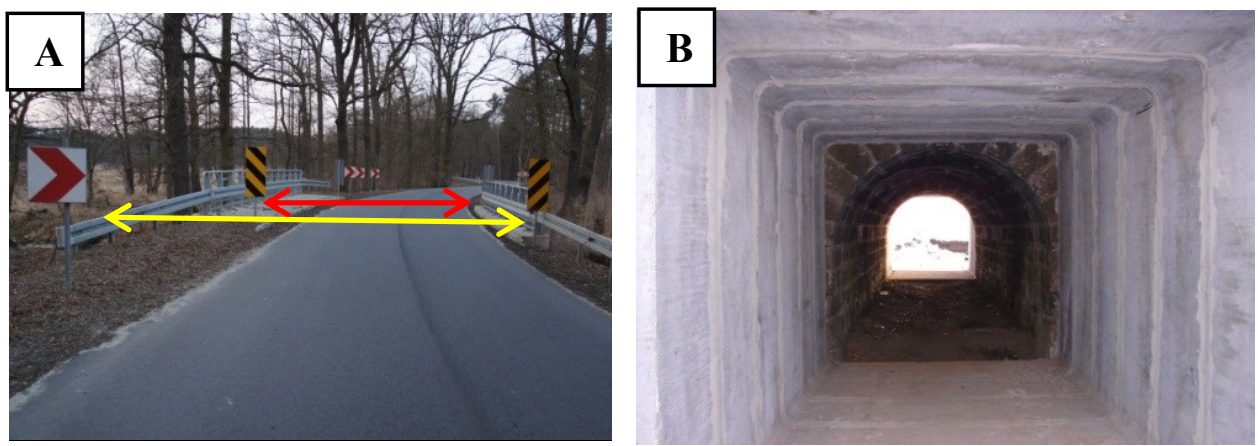

Fig. 8. Examples of the extension of the structure with the use of additional supporting structures: a) extension of the facility using relining technology to enable the bicycle path to be made (photo A. Wysokowski), b) a view of the completed facility extension by open excavation using reinforced concrete prefabricated box sections (photo. by Z. Kubiak).

\subsection{Reinforcing culverts using the cured composite sleeve}

The renovation technology in question consists in placing, without interfering with the external structure of the culvert, a special liner matched to the shape of the duct, in the form of a sleeve soaked in polymer resin, and then hardening it to meet the required strength parameters for a given object [10]. As a result of the hardening process, the sleeve fully seals damaged wire, covers cracks and cracks. The hardened sleeve also begins to form an independent load-bearing structure in the form of a construction element, for which the existing object is a form of "lost formwork", allowing only the assembly of sleeves. In this innovative technology, at the beginning of its application, the sleeve was not an essential structural element.

In addition to making the sleeve, depending on the needs, carbon, polymer, glass fibers or a combination of these fibers can also be used - to achieve the best strength results. An innovative curing process using ultraviolet radiation has now been developed. Curing occurs as a result of local UV radiation thanks to gradual movement of lamps through the interior of the coating in which there is constant overpressure.

It should be noted that thanks to the innovative obtained by the curing process, the sleeve bearing can be used as individual component. The new construction is then made on the route of an existing, reinforced object, which does not need to be demolished, and the existing structure is a form of lost shuttering, allowing only the assembly of the sleeve. Then, as the practice shows, the object being amplified works holistically as an integrated composite structure (cooperating shell with the surrounding material).

Figure 9 presents a practical example of the renovation of a reinforced concrete culvert structure using the technology in question.

\subsection{Renovation of culverts using modern construction chemistry products}

In the case of objects with small structural damage, or historical objects, where we cannot interfere to a large value of their architecture, traditional renovation methods should be used. They mainly consist in the use of modern construction materials and chemistry in the form of special mortars, and injection materials. Strengthening these structures involves structural filling of existing cavities, scratches and cracks, as well as later anti-corrosion protection. 

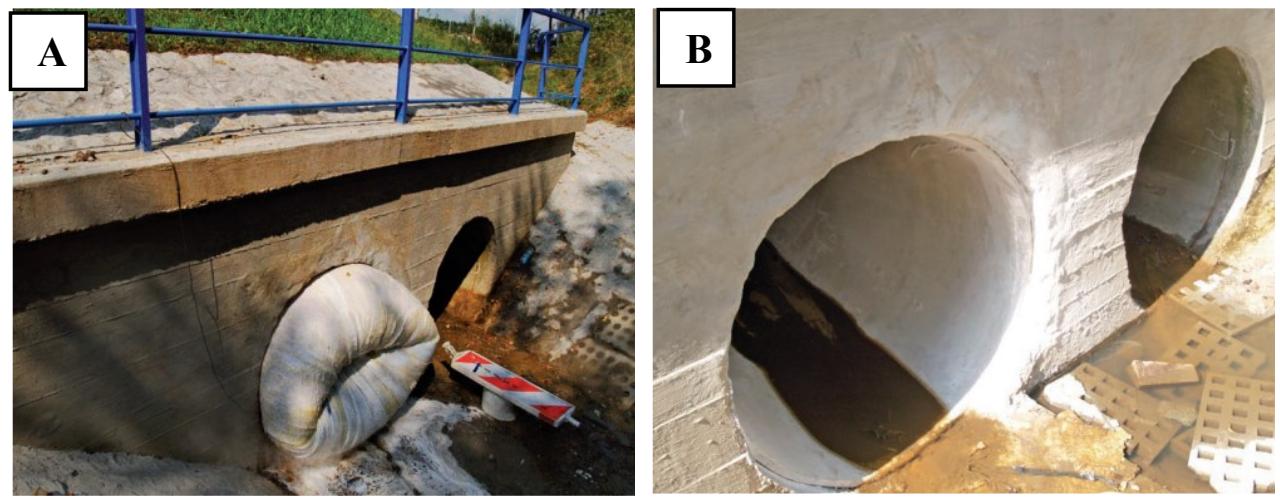

Fig. 9. Example restoration passage by a sleeve impregnated with a cured polyester resin: a) view of the structure at the stage of reinforced - "cured" - a reinforcing sleeve, b) the back realized object after curing of the coating [11].

The basic problem that must be solved before attempting to repair the culvert is the right choice of repair material. This material must ensure the effectiveness of the repair and durability, so that the object subjected to repair works safely and has all the required functional characteristics. It should be remembered that after the repair, the culvert will constitute a specific system of materials cooperating with each other: repair material and material of the repaired facility. This system works in the conditions of external interactions of a mechanical nature (usable loads), thermal and chemical (impact of aggressive factors). For such a system to work properly, a number of conditions regarding the properties of both materials must be met. According to the author's many years of experience, it is recommended to use materials included in the repair systems. Using method above, compatibility of materials, i.e. the material of the existing structural structure and the repair material, must be taken into account. Compatibility in this case means compatibility or similarity of mechanical, physical and chemical properties of the repair and repair material.

Figure 10 shows an example of the renovation of a road building with the use of modern solutions in the field of construction chemistry.

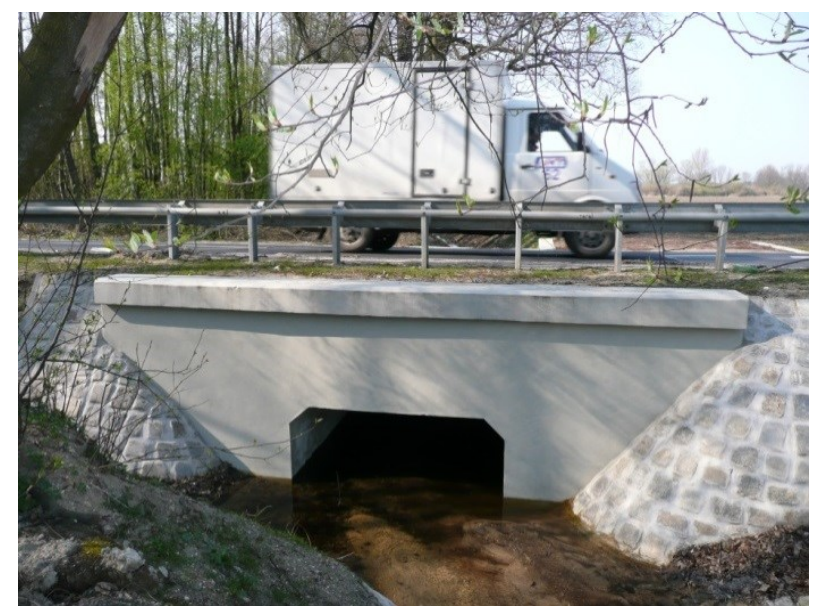

Fig. 10. Example of renovation of a road facility with the use of modern construction materials (photo by Author). 


\section{Calculation methods for reinforcing culvert structures}

The basic problem when designing structures embedded in the ground is to determine the size and distribution of loads acting on their external surface. The size and distribution of stresses from external loads, and above all from the weight of the ground located above the structure depends on the rigidity of the supporting structure of the culvert.

In the case of objects requiring reinforcement, while choosing calculation methods, one should take into account the fact that the existing culvert structure should be treated as a part of the backfill co-operating with the new bearing structure.

Table 2 summarizes the calculation methods for the discussed structures.

Table 2. Currently used calculation methods of culvert structures.

\begin{tabular}{|c|c|}
\hline Method & Short description of the method \\
\hline The Ring Compression Theory & $\begin{array}{l}\text { - assumes that the ground pressure is small, } \\
\text { - the structure is subjected to constant compression, } \\
\text { - does not include the deflection criterion, }\end{array}$ \\
\hline $\begin{array}{l}\text { American Association of State } \\
\text { Highway and Transportation } \\
\text { Officials (AASHTO) }\end{array}$ & $\begin{array}{l}\text { - does not include bending moments, } \\
\text { - possibility of designing a construction with a } \\
\text { frame cross-section, }\end{array}$ \\
\hline Duncan \& Drawski Method & $\begin{array}{l}\text { - the influence of bending moments and axial } \\
\text { forces is taken into account, } \\
\text { - buckling criterion is ignored, }\end{array}$ \\
\hline $\begin{array}{l}\text { Ontario Highway Bridge } \\
\text { Design Code (OHBDC) }\end{array}$ & $\begin{array}{l}\text { - the influence of permanent axial forces on the } \\
\text { whole circumference } \\
\text { - for flexible materials, }\end{array}$ \\
\hline $\begin{array}{l}\text { Canadian Highway Bridge } \\
\text { Design Code (CHBDC }\end{array}$ & $\begin{array}{l}\text { - the possibility of designing a box-shaped } \\
\text { structure, }\end{array}$ \\
\hline Vaslestad Method & $\begin{array}{l}\text { - assumes that a significant part of the loads is } \\
\text { transferred through the ground, } \\
\text { - ignores the effect of bending moments, } \\
\text { - recommended for the design of structures with } \\
\text { large spans, }\end{array}$ \\
\hline Klopela \& Glöck Method & $\begin{array}{l}\text { - was created on the basis of destructive research, } \\
\text { - assumes that the ground carries more loads than } \\
\text { the pipe itself, }\end{array}$ \\
\hline Analytical Elastic Method & $\begin{array}{l}\text { - soil and culvert as a linear-elastic material, } \\
\text { - objects covered with high overfill, }\end{array}$ \\
\hline Sundquist-Petterson Method & $\begin{array}{l}\text { - studies on real models, } \\
\text { - universality, }\end{array}$ \\
\hline $\begin{array}{l}\text { The Scandinavian Method - } \\
\text { calculation of flexible buried } \\
\text { culverts }\end{array}$ & $\begin{array}{l}\text { - use of buried flexible culverts, } \\
\text { - deflection is the basic design criterion, }\end{array}$ \\
\hline Finite Element Method (FEM) & $\begin{array}{l}\text { - application to plastic culverts, } \\
\text { - deflection is the basic design criterion, }\end{array}$ \\
\hline
\end{tabular}

The calculation procedures according to the above methods have been described in many publicly available references, to which the author refers readers. It should be borne in mind that these methods were created over a different period of time and were based on the knowledge available at that time. They are successively improved and take into account many important parameters. 
According to the author's experience, most of these methods are "conservative" and the results obtained according to them have inventories in relation to the research of real objects.

When calculating reinforcing structures (e.g. in the relining method), unlike new ones, one should also take into account - especially when collecting constant loads - that the existing structure constitutes an additional burden in the initial phase of the communication pass passage. In the later phase of operation, the existing object cooperating with the structure through its gradual degradation - in effect creates a quasi-homogeneous ground center cooperating with the susceptible structure. In this case, there is a certain difficulty in the proper selection of calculation methods. The basic problem encountered when designing structures embedded in such a "complicated" center is to determine the size and distribution of loads acting on their external surface. To a large extent, these difficulties result from the random and rheological nature of factors affecting the work of the structure.

Current calculation methods (mainly traditional methods) are different from each other, which can cause frequent over-dimensioning and makes it difficult to verify results. The fact is that the ground center is not only a building load, but also a load bearing element. The effect of cooperation between the structure and the ground is to improve the load distribution and, consequently, the load is evenly distributed around the cross-section, the result of which bending moments have a lower value $[12,13]$. In the described case, due to the "complicated" computational structure, the most effective methods are computer methods using the finite element method - FEM with proper consideration of the "work" parameters of the new and existing structure. The essence, and at the same time the fundamental difference between the finite element method and the analytical methods used to design a structure, is that it allows building a closer reality of the object model (a complex structure) [14]. As a result, phenomena occurring in the analyzed centers are modelled in a manner similar to the actual distribution of stresses $[15,16]$.

\section{Conclusions}

This paper deals with important issues related to the need to rebuild and strengthen the culvert structures and animal crossings. As mentioned at the outset, their role in the national communication infrastructure is no less important as often as spectacular bridge structures. The paper deals in a synthetic way with issues related to both methods of strengthening the discussed objects, as well as the calculation principles used in this case.

In order to select the reinforcement technology appropriately, this paper focuses on the types of materials used in the renovation of culverts, and the methods of selecting a reinforcing structure. When selecting these methods, the durability of the reinforcement is also very important. The choice of the method should be developed taking into account both durability engineering as well as observing the principles of sustainable development. In addition, the necessity to ensure the continuity of road traffic or its minimization is not without significance, which reduces the social costs incurred in this type of investment.

According to the author, the appropriate selection of reinforcement or renovation technology allows achieving the assumed durability of the facility while minimizing material and economic expenses. The use of optimal, sustainable engineering solutions for renovating the culverts structures brings benefits to both users of transport infrastructure and the natural environment. 


\section{References}

1. A. Wysokowski. Arch. Inst. Civ. Eng., 23, pp. 347-361 (2017) [in Polish]

2. P. Dmowski P, Geo-Eng Roads Brid. Tunn., 20, pp. 66-69 (2009) [in Polish]

3. A. Wysokowski, A. Staszczuk, T. Nowak, Materiały Budowlane, 2, 39-41 (2009) [in Polish]

4. L. Janusz, A. Madaj, Buried flexible steel structures. Designing and execution, (Transport and Communication Publishers, Warsaw, Poland 2007) [in Polish]

5. K. Frydrychowska, K. Kozińska, Strengthening methods of communication culverts. (Master thesis, University of Zielona Góra, Zielona Góra 2009) [in Polish]

6. A. Kuliczkowski, P. Dańczuk, Nowoczesne Budownictwo Inżynieryjne, May-June, pp. 93-96 (2008) [in Polish]

7. W. Rowińska, A. Wysokowski, A. Pryga, Design and technology recommendations for flexible road engineering constructions from corrugated steel plates (GDDKiA IBDiM, Żmigród, Poland, 2004) [in Polish]

8. W. Jasiński, A. Łęgosz, A. Nowak, A. Pryga-Szulc, A. Wysokowski, Design and technology recommendations for flexible road engineering constructions from plastic pipes (GDDKiA-IBDiM, Żmigród, 2006) [in Polish]

9. A. Wysokowski, J. Howis, Nowoczesne Budownictwo Inżynieryjne, 6, pp. 94-99, [in Polish]

10. C. Madryas, A. Kolonko, L. Wysocki, Construction of sewage pipes (Wroclaw University of Technology Publishing House, Wroclaw, 2002) [in Polish]

11. P. Mazur, Nowoczesne Budownictwo Inżynieryjne, September-October, pp. 44-45 (2009) [in Polish]

12. B. Kunecki, Behaviour of orthotropic buried arch shells under static and dynamic live loads (Wroclaw University of Technology Publishing House, Wroclaw, 2008) [in Polish]

13. A. Wysokowski, J. Howis, Nowoczesne Budownictwo Inżynieryjne, SeptemberOctober. pp. 72-81 (2010) [in Polish]

14. Cz. Machelski, Calculations for buried shell bridges (Lower Silesia Educational Publishing, Wrocław, Poland, 2008) [in Polish]

15. K.M. El-Sawy, Thin Wall. Struct., 41(8), pp. 747-768 (2003)

16. B. Chen, D. Song, X. Mao, E.J. Chen, J. Zhang, Comput. Geotech., 79, pp. 31-40 (2016) 